\title{
HER2+ breast cancer treatment and cardiotoxicity: monitoring and management
}

\author{
Guy Jerusalem ${ }^{1}$ [ $\cdot$ Patrizio Lancellotti ${ }^{2} \cdot$ Sung-Bae Kim $^{3}$
}

Received: 21 May 2019 / Accepted: 27 May 2019 / Published online: 5 June 2019

(C) The Author(s) 2019

\begin{abstract}
Background Breast cancer is a leading cause of death for women worldwide, with incidence increasing in lower-income countries. For patients with human epidermal growth factor receptor-2-positive (HER2+) breast cancer, widespread availability of several agents targeting the HER2 receptor has resulted in survival gains over the past decades. However, improved survival has resulted in an increased need for management and mitigation of adverse events associated with anticancer therapy. Cardiac adverse events such as decreased ejection fraction and heart failure have been of particular concern in patients with HER2+ breast cancer. Anti-HER2 agents and chemotherapies (specifically anthracyclines, which are frequently used to treat HER2+ disease) have been associated with cardiotoxicity. As increasing numbers of patients are living longer due to more effective therapy, a better understanding of both monitoring and management of cardiotoxicity is urgently needed. Methods A comprehensive review of the literature was conducted via PubMed in January 2018 for phase II and phase III trials of "trastuzumab", "lapatinib", "pertuzumab", "T-DM1", "neratinib", in "breast cancer". Literature was evaluated for content related to cardiac adverse events.

Findings We describe the incidence of and proposed mechanisms for the cardiotoxicity of available HER2-targeted therapies. We summarize current and emerging practices in the management of cardiotoxicity and provide guidance for routine patient care in real-world practice using illustrative patient scenarios.

Conclusions The future of cardiotoxicity management in patients with HER2+ breast cancer is discussed, with a focus on novel techniques to improve cardiac outcomes, including new imaging modalities, biomarkers, interventional therapies, and ongoing trials.
\end{abstract}

Keywords Breast neoplasms $\cdot$ Cardiotoxicity $\cdot$ Trastuzumab $\cdot$ Anthracyclines

$\begin{array}{ll}\text { Abbreviations } \\ \text { ACE } & \text { Angiotensin converting enzyme } \\ \text { AE } & \text { Adverse event } \\ \text { ASCO } & \text { American Society of Clinical Oncology } \\ \text { CHF } & \text { Congestive heart failure } \\ \text { CMR } & \text { Cardiac magnetic resonance }\end{array}$

Guy Jerusalem

g.jerusalem@chu.ulg.ac.be

1 Department of Medical Oncology, Centre Hospitalier Universitaire du Sart-Tilman, University of Liege, Liège, Belgium

2 GIGA Cardiovascular Sciences, Department of Cardiology, Centre Hospitalier Universitaire du Sart-Tilman, University of Liege, Liège, Belgium

3 Asan Medical Center, University of Ulsan College of Medicine, 88, Olympic-ro 43-gil, Songpa-gu, Seoul 05505, Korea
CRP C-reactive protein

EGFR Epidermal growth factor receptor

ESC European Society of Cardiology

ESMO European Society for Medical Oncology

GDF-15 Growth differentiation factor-15

GLS Global longitudinal strain

HER2+ Human epidermal growth factor receptor-2-positive

LVEF Left ventricular ejection fraction

MBC Metastatic breast cancer

MPO Myeloperoxidase

NCCN National Comprehensive Cancer Network

STE Speckle tracking echocardiography

TDI Tissue Doppler imaging

T-DM1 Trastuzumab emtansine

TKI Tyrosine kinase inhibitor 


\section{Introduction}

Human epidermal growth factor receptor-2 (HER2+) breast cancers compose approximately $15 \%$ of all breast cancers and are more likely to be diagnosed in younger patients and at a more advanced stage than the more common hormone receptor-positive, HER2-negative breast cancers [1]. However, treatments that specifically target the HER2 receptor have significantly improved survival rates for patients with both early- and advanced-stage disease [2]. Currently, several anti-HER2 therapies have been approved for the treatment of advanced and/or early breast cancer and additional agents are in late-stage clinical development (Table 1) [3-15].

Current guidelines for the management of HER2+ disease focus on optimal disease control with limited toxicity by combining sequential HER2-targeted therapy with chemotherapy [16-19]. As treatment efficacy increases, there are increasing numbers of patients who survive for extended periods and may receive therapy for a prolonged duration. Therefore, patients increasingly require longterm management of treatment morbidities. Cardiac health is an issue of special concern for HER2+ breast cancer as both chemotherapy and HER2-targeted therapies can cause cardiotoxicity [20,21]. Better awareness of the late effects of treatment-related cardiotoxicity and strategies for longterm management are urgently needed. Here, we review the cardiotoxicity risks of HER2-targeted therapies and the currently recommended clinical guidelines for monitoring and management. We further summarize emerging techniques for the identification, treatment, and monitoring of patients with increased risk of cardiotoxicity.

\section{Cardiotoxicity of currently available HER2-targeted therapies}

Anticancer agents in routine clinical use may cause cardiac damage via several distinct mechanisms. This may include irreversible damage (Type 1; e.g., with chemotherapeutic agents such as anthracyclines), or reversible dysfunction (Type 2; e.g., with HER2-targeted therapies) [22] (Fig. 1). Although many therapies carry a risk of cardiotoxicity, types and rates of cardiac adverse events (AEs) reported in the literature vary widely (Table 2) $[3-5,7-10,12,14$, 15, 21, 23-29]. As increasing numbers of patients are being treated with HER2-targeted therapies for extended periods of time, frequently with multiple agents and/or in combination with anthracycline-based chemotherapy, it is essential to fully understand these mechanisms to implement appropriate clinical monitoring and management.

\section{Trastuzumab}

Trastuzumab is frequently associated with an increased risk of cardiotoxicity, with $3 \%$ to $7 \%$ of patients who received trastuzumab monotherapy in clinical trials experiencing some form of cardiac dysfunction [23]. Although the mechanism for trastuzumab-associated cardiac dysfunction is not fully understood, it has been suggested that cardiomyocyte death occurs via multiple pathways, including as the direct result of ErbB2 (HER2) blockade and the increased production of reactive oxygen species [30, 31].

Administration of trastuzumab after prior treatment with anthracyclines may contribute to the relatively high levels of cardiotoxicity reported in clinical trials [32]. Although up to $75 \%$ of patients in clinical trials of trastuzumab who exhibited cardiac dysfunction were symptomatic, the majority of these had prior treatment with anthracyclines [23]. In contrast, there is a low incidence of symptomatic heart failure and decline in asymptomatic left ventricular ejection fraction (LVEF) among patients receiving trastuzumab without an anthracycline [23, 32]. In addition to the risks of trastuzumab administered with chemotherapy, concomitant radiotherapy to the left breast (or left thoracic wall) may be associated with an increase in long-term cardiotoxicity risk, although this phenomenon is not yet fully understood [33]. More research is needed to better understand the potential cardiac risks of trastuzumab, and multimodal therapies frequently used to treat aggressive disease.

Both clinical trial data and real-world evidence suggest an increased risk of cardiotoxicity with trastuzumab treatment. In the initial phase 3 trial of trastuzumab in patients with HER2+ metastatic breast cancer (MBC), $27 \%$ of patients receiving trastuzumab plus chemotherapy experienced cardiac dysfunction, compared with $8 \%$ of patients receiving chemotherapy alone [3]. Across seven trials in patients with $\operatorname{MBC}(N=1497)$, the risk of cardiac toxicities was significantly increased in patients receiving trastuzumab-containing regimens compared with regimens that did not contain trastuzumab, even though normal cardiac function was an entry criterion for all but the initial trial [24]. Risks of both serious cardiac dysfunction [including congestive heart failure (CHF)] and LVEF decline were significantly increased in patients receiving trastuzumab, irrespective of whether it was administered as a first-line treatment or beyond disease progression [24]. In a real-world cohort of patients receiving trastuzumab for primary or MBC $(N=388)$, cardiotoxicity occurred at a higher-than-expected rate and occurred more frequently in patients who were older and had prior treatment with an anthracycline [34]. These data confirm the need for cardiac monitoring throughout treatment, particularly for patients with MBC, who are more likely to be older and to have received prior anticancer therapy. 


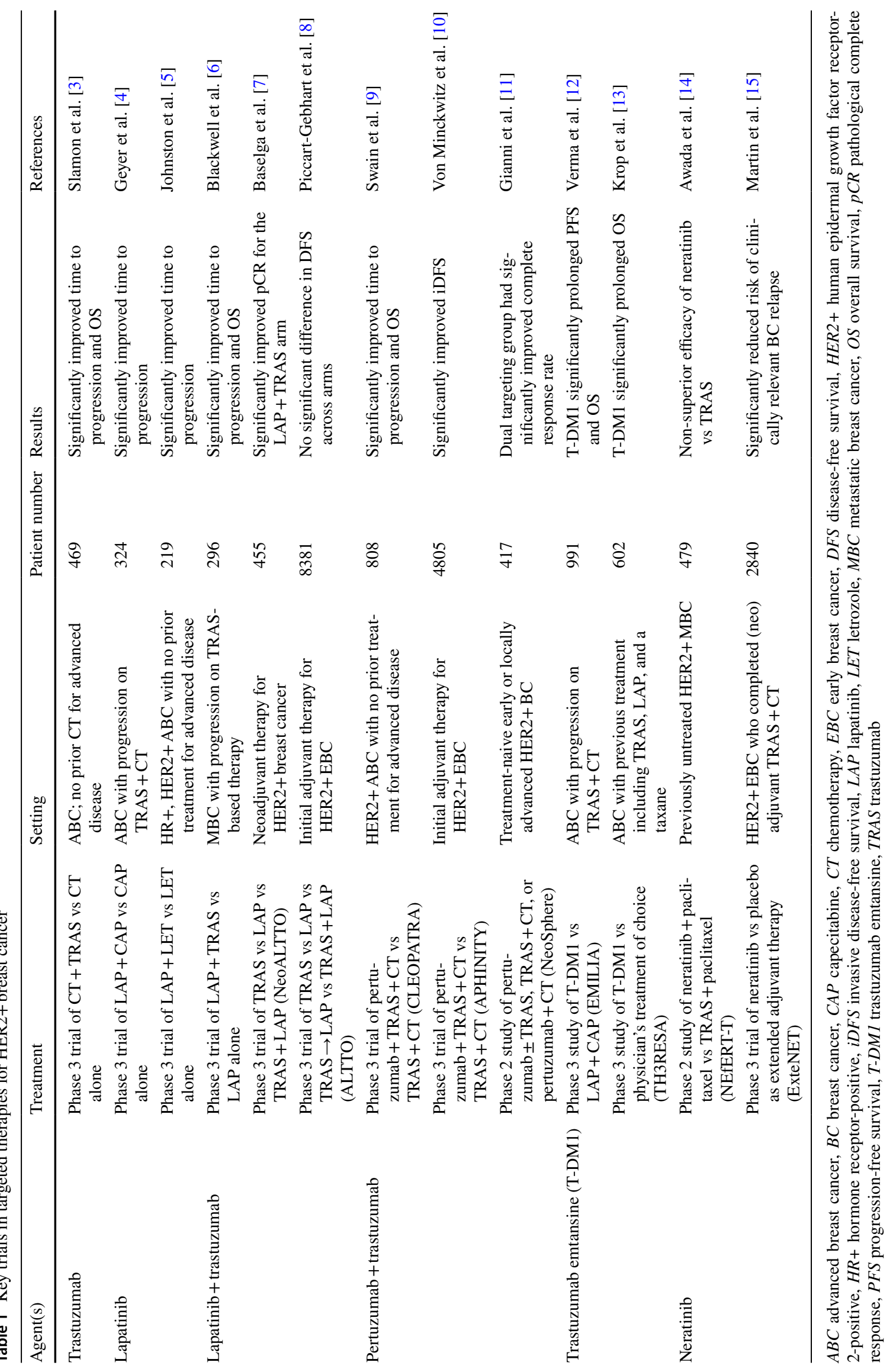




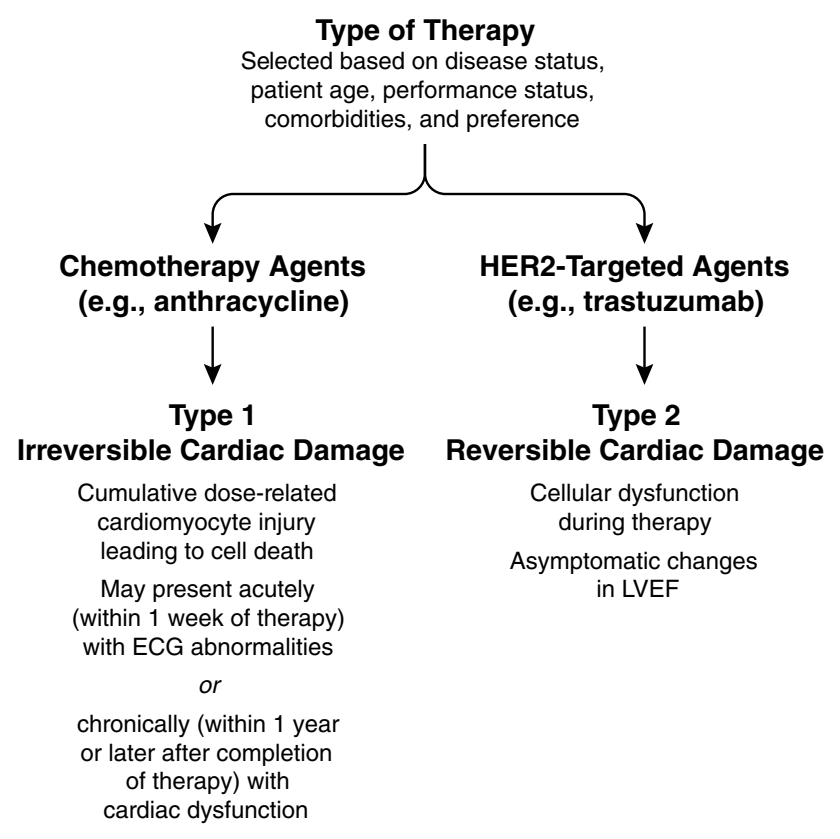

Fig. 1 Schematic of Potential Mechanisms of Cardiotoxicity. There are 2 types of therapy selected based on disease status, patient age, performance status, comorbidities, and preference. Chemotherapy agents such as anthracycline can lead to irreversible (type 1) cardiac damage. With type 1 damage, cumulative dose-related cardiomyocyte injury leading to cell death can occur and may present acutely (within 1 week of therapy) with ECG abnormalities or chronically (within 1 year or later after completion of therapy) with cardiac dysfunction. HER2-targeted agents such as trastuzumab can lead to reversible (type 2) damage. With type 2 damage, cellular dysfunction during therapy and asymptomatic changes in LVEF can occur. ECG electrocardiogram, HER2 human epidermal growth factor receptor-2, LVEF left ventricular ejection fraction

In the adjuvant setting, long-term safety and late-onset AEs are issues of special concern because patients may receive treatment for an extended duration. A meta-analysis study reported increased risk of asymptomatic LVEF decrease and symptomatic heart failure with adjuvant trastuzumab [24]. Although overall incidence is low, adjuvant trastuzumab has been associated with a significant increase in risk of serious cardiac events such as CHF [21]. Cardiotoxicity remains an issue of special concern when trastuzumab is combined with an anthracycline in the adjuvant setting even though therapies are administered sequentially [35]. A Dutch study of patients receiving trastuzumabbased adjuvant therapy in a real-world setting $(N=230)$ reported cardiotoxicity in $12.6 \%$ of patients, with $8.7 \%$ of these patients experiencing symptomatic cardiotoxicity [36]. An Italian study of women receiving trastuzumab for early breast cancer $(N=499)$ noted even higher rates of cardiotoxicity, with $27 \%$ of patients experiencing LVEF decrease [37]. Importantly, both studies note that trastuzumab-related cardiotoxicity appears early in the course of treatment ( $\leq 6$ months of therapy), highlighting the crucial need for early monitoring $[36,37]$. Indeed, the trastuzumab label includes guidance to monitor cardiac function before starting treatment, at regular intervals throughout the course of therapy, and every 6 months for at least 2 years after completion of adjuvant therapy [38, 39].

\section{Lapatinib}

Lapatinib, an epidermal growth factor receptor (EGFR) and HER2 dual tyrosine kinase inhibitor (TKI), is infrequently associated with cardiac AEs such as decreased LVEF in clinical trials $[4,5,29]$. A meta-analysis demonstrated that the majority of patients treated with lapatinib in clinical trials who had decreased LVEF was asymptomatic and that the effect was largely reversible with treatment interruption [29]. It is important to note that the majority of patients in clinical trials of lapatinib was previously treated with trastuzumab but was excluded from these trials if prior cardiac toxicity was observed. Although a meta-analysis of data for patients receiving lapatinib in clinical studies demonstrated similar rates of LVEF decline with or without trastuzumab or anthracycline pretreatment [29], the ALLTO trial allowed a head-to-head comparison between trastuzumab and lapatinib and demonstrated fewer cardiac events (including CHF and LVEF decrease) with lapatinib versus trastuzumab at 1 year [8]. As lapatinib is frequently administered to patients who have previously received therapy with trastuzumab and/or anthracycline-based chemotherapy, label guidance indicates LVEF monitoring at baseline and during treatment [40, 41].

The possibility of dual targeting with lapatinib and trastuzumab was explored in several large phase 3 clinical trials. In the neoadjuvant setting, cardiac AEs occurred at a low rate in patients receiving both trastuzumab and lapatinib with paclitaxel (one patient in each group experienced LVEF decrease) [7]. In contrast, in the adjuvant setting there was a higher incidence of AEs in patients receiving both lapatinib and trastuzumab, including cardiac endpoints (LVEF decrease or CHF) [8]. In the metastatic setting, the combination of lapatinib and trastuzumab resulted in a low incidence of cardiac events across treatment arms, which was notable as all patients had received prior lines of therapy that included both trastuzumab and an anthracycline [6]. Although duration of exposure to anti-HER2 therapies may have been shorter in the metastatic setting trials than in the adjuvant setting, these data overall indicate that the addition of lapatinib to trastuzumab does not drastically increase the risk of cardiac events over that associated with trastuzumab alone.

\section{Pertuzumab}

As pertuzumab is administered in combination with trastuzumab for both early-stage and metastatic breast cancer, 


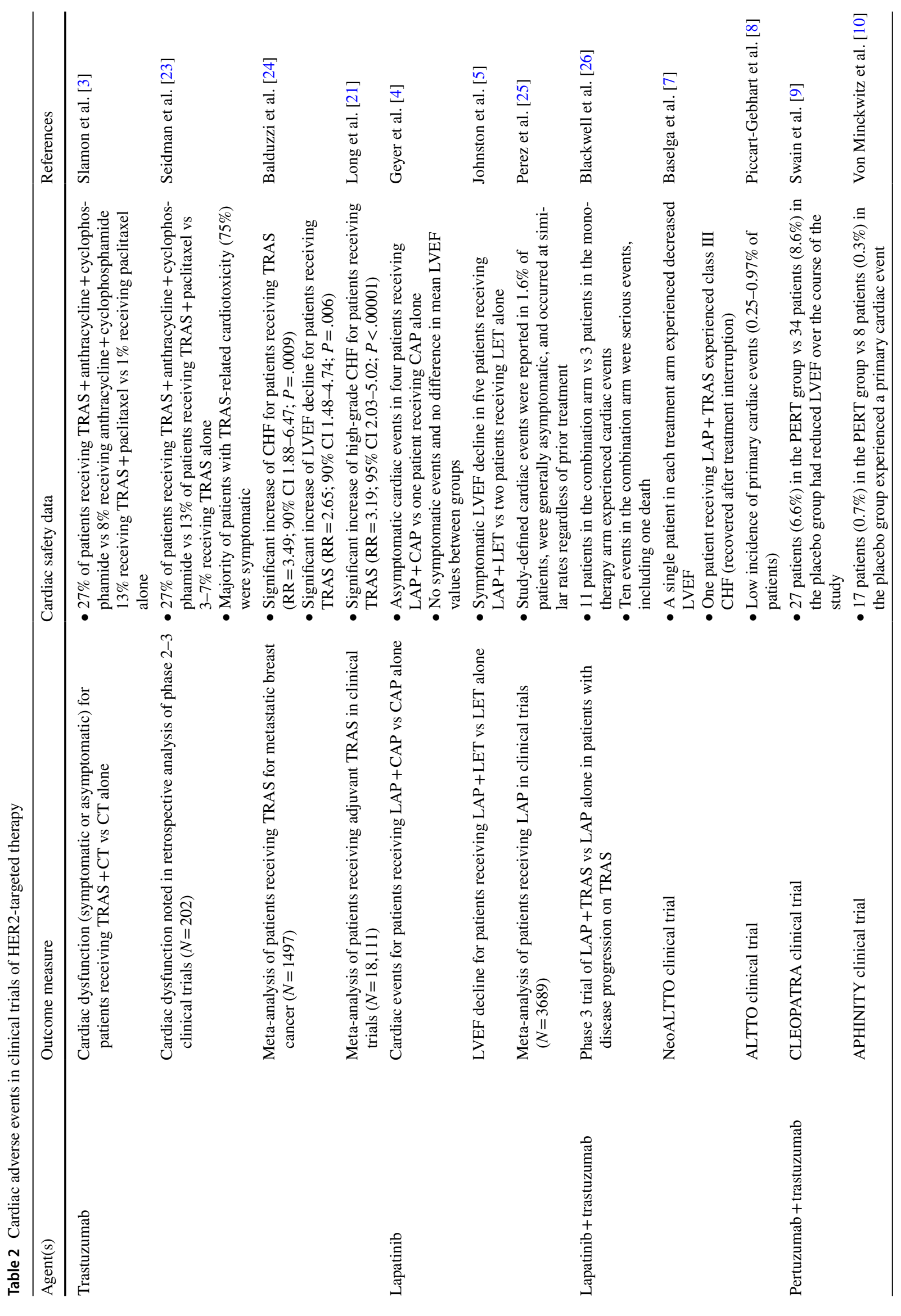


cardiotoxicity has been evaluated in several clinical trials. For patients receiving pertuzumab plus trastuzumab and docetaxel for HER2+ metastatic breast cancer in the phase 3 CLEOPATRA clinical trial, the long-term rate of cardiotoxicity was slightly lower than for patients receiving placebo plus trastuzumab and docetaxel [9]. Similarly, patients receiving pertuzumab in addition to standard adjuvant chemotherapy and 1 year of trastuzumab for early breast cancer in the APHINITY trial experienced low rates of cardiac events [10]. For patients receiving pertuzumab in the neoadjuvant setting, the phase 2 NeoSphere study reported a low incidence of cardiac events across treatment arms [11]. Finally, an analysis of 57 patients receiving pertuzumab-based combination therapy in a real-world setting did not note an increased risk of cardiotoxicity compared with sequential chemotherapy and trastuzumab [42]. However, as the available cardiac safety data are limited and as pertuzumab is often administered with anthracyclines and/or trastuzumab, the label carries a warning for LVEF decrease [43, 44].

\section{Trastuzumab emtansine (T-DM1)}

T-DM1 is indicated for use as a single agent for metastatic HER2+ cancer after failure of trastuzumab [45]. The phase 3 TH3RESA and EMILIA clinical trials in previously treated HER2+ metastatic breast cancer noted similarly low rates of LVEF decrease for patients receiving T-DM1 or an alternate therapy (including trastuzumab or lapatinib plus chemotherapy or chemotherapy alone) $[12,27]$. Initial clinical trials in the adjuvant setting noted that rates of LVEF decrease were lower than those observed in trials of trastuzumab plus chemotherapy, even after prior treatment with anthracyclines [46]. In the phase 3 MARIANNE trial, fewer patients treated with T-DM1 experienced LVEF decrease compared with those treated with trastuzumab plus a taxane [29]. The low rate of cardiac events was confirmed in a retrospective analysis of 250 patients receiving T-DM1 for metastatic disease in a real-world setting [47]. Although rates for cardiac AEs with T-DM1 were generally low, the drug label includes a warning for cardiotoxicity due to LVEF decrease, which may be of particular concern because the drug is indicated for patients with prior treatment including both trastuzumab and a taxane $[45,48]$.

\section{Neratinib}

Neratinib, a TKI approved in 2017 for treatment of HER 2+ breast cancer, was not associated with grade 3/4 cardiotoxicity for patients in a phase 2 trial, and little variation in LVEF versus baseline was noted across patients regardless of prior trastuzumab treatment [49]. Cardiotoxicity in phase 3 trials (ExteNET and NEfERT-T) was minimal and followup continues for monitoring of cardiac AEs $[14,50]$. No 
evidence of increased long-term toxicity, specifically symptomatic cardiotoxicity, was observed in patients receiving neratinib in the adjuvant setting [15]. Neratinib is approved for use in the adjuvant setting following trastuzumab-based therapy and currently does not carry a warning for cardiotoxicity [51].

\section{Clinical monitoring and management of cardiotoxicity}

\section{Current approaches}

Guidelines for the monitoring and management of treatmentinduced cardiotoxicity are available from the European Society for Medical Oncology (ESMO), the National Comprehensive Cancer Network (NCCN), the American Society of Clinical Oncology (ASCO), and the European Society of Cardiology (ESC) [17, 19, 52, 53]. When creating a treatment plan the individual risk factors for each patient must be carefully considered to choose both the appropriate therapy and the necessary cardiac monitoring plan. Although ongoing monitoring is recommended for patients receiving trastuzumab therapy, all guidelines note that the optimal interval has not been determined. As cardiotoxicity due to HER2targeted therapy is well recognized, patients at increased risk for cardiac events are frequently excluded from trials, leaving little evidence for the treatment of patients with baseline cardiac disease, a common scenario in clinical practice. This underscores the need for studies such as the ongoing SAFEHEaRT trial in patients with mild reductions in LVEF [54].

Interruption or cessation of HER2-targeted therapy is recommended if significant LVEF decrease is detected during treatment. However, several retrospective analyses of patients receiving trastuzumab in a real-world setting have noted LVEF monitoring is not generally performed as recommended in current guidelines $[55,56]$. The discordance between clinical guidelines and real-world practice is further confounded by the fact that although serial LVEF monitoring during trastuzumab treatment is recommended, some debate exists as to the optimal frequency and utility of LVEF changes in predicting heart failure or in deciding on a change in treatment [57, 58]. Although the trastuzumab label recommends monitoring at baseline and every 3 months of treatment (with further monitoring recommended for patients who receive therapy in the adjuvant setting), the cost of this testing and the relatively low rate of patients requiring therapeutic intervention for symptomatic cardiac events keep this issue as a topic of debate $[38,59]$. In particular, young patients with no history of cardiac disease may not derive significant benefit from cardiac monitoring and long-term follow-up [60].
Detection of clinically significant cardiac dysfunction before or during treatment may result in additional interventions beyond change of treatment plan. In patients with a high risk of cardiac dysfunction receiving anthracycline chemotherapy, dexrazoxane may be administered to reduce the risk of cardiotoxicity [61]. Although current evidence is limited, several studies suggest that standard treatments for cancer therapy-induced LVEF decrease and heart failure, such as angiotensin-converting-enzyme (ACE) inhibitors or beta-blockers, may preserve cardiac function in patients receiving trastuzumab or chemotherapy $[62,63]$. Trials evaluating preventive treatments, such as the SAFE trial, are ongoing, with results eagerly anticipated [64].

\section{Considerations for special populations}

Selection of treatment for patients with HER2+ breast cancer in either the adjuvant or advanced setting must balance potential benefits of treatment with risk for AEs. When specifically assessing the risk of cardiotoxicity, certain populations are at an elevated risk and pose a further challenge to the clinician in selecting an ideal treatment. These populations may have been excluded from (or under-represented in) clinical trials and require further evaluation. To illustrate the complex decisions that may face physicians, we describe 2 hypothetical case studies demonstrating common clinical scenarios.

\section{Hypothetical case study 1}

Despite the fact that cancer incidence increases with age, elderly patients are less frequently included in clinical trials, more frequently have comorbidities, and may be more likely to experience AEs [65]. Elderly patients are at a greater risk of developing cardiotoxicity due to cancer therapy, frequently due to an increased prevalence of underlying cardiac risk factors and common comorbidities such as diabetes and hypertension [53, 66]. However, cardiotoxicity data on elderly patients receiving HER2-targeted therapy are limited. A meta-analysis in patients receiving trastuzumab for HER2+ breast cancer in routine clinical practice found that elderly patients had a significantly increased risk of cardiac toxicity compared with younger patients [67]. A similar retrospective analysis of Medicare data noted that elderly patients receiving trastuzumab and/or chemotherapy experienced $\mathrm{CHF}$ at a higher rate than that observed in clinical trials, and that the risk increased with advancing age [68].

In this case, the patient has experienced disease recurrence after receiving prior trastuzumab therapy (Fig. 2). Given her history of cardiotoxicity, precaution must be taken when deciding on a course of treatment including targeted therapy for metastatic disease. Based on the patient's age, treatment history, and potential comorbidities, careful 
A 72-year-old woman was diagnosed with high-risk estrogen receptor-negative (ER-)/progesterone receptor-negative $(\mathrm{PgR}-)$ /human epidermal growth factor receptor-2-positive (HER2+) Stage IIIB breast cancer 3 years ago $(5 \mathrm{~cm}$, poorly differentiated ductal carcinoma with 4 positive lymph nodes; Ki67 expression 60\%). She received 4 cycles of epirubicin plus cyclophosphamide $(E C \times 4)$, followed by weekly trastuzumab plus paclitaxel prior to surgery. After 3 months of adjuvant trastuzumab therapy, treatment was stopped due to asymptomatic left ventricular ejection fraction (LVEF) decrease noted on routine heart ultrasound. Three months after stopping trastuzumab therapy LVEF fully recovered, but trastuzumab was not restarted in the adjuvant setting. She now presents with liver metastases after elevated liver enzymes were noted during a routine blood test.

Fig. 2 Hypothetical case study 1

consultation with a cardiac oncology team should be sought before beginning treatment.

\section{Hypothetical case study 2}

Heart disease and additional comorbidities that may increase risk of cardiovascular disease (such as diabetes) are increasingly common [69]. The presence of chronic disease (including atrial fibrillation, ischemic heart disease, poorly controlled hypertension, and diabetes) can complicate cancer treatment [70]. The lack of prospective clinical trial data on patients with pre-existing cardiac disease further confounds the ability of physicians to select the appropriate anticancer therapy while appropriately continuing treatment for cardiac disease.

In this case, the patient is already under a cardiologist's care, so her baseline disease status and associated risk of AEs are clearly established (Fig. 3). However, many patients may not have received prior medical treatment, or may have subclinical cardiac disease that is unknown to them. Full assessment of cardiac function for each patient should take place before the start of treatment, and careful monitoring should be followed to reduce risk [71]. For patients with notable cardiac disease at baseline, early integration of a cardiologist or cardio-oncology team into treatment planning is essential for effective and safe disease management. Regardless of age or baseline status, every effort should be made to provide patients with an appropriate level of care to manage their breast cancer and concomitant cardiac health conditions.

\begin{abstract}
A 58-year-old woman is under cardiologist care for ischemic heart disease (myocardial infarction 9 months prior). She has recently been diagnosed with intermediate-risk estrogen receptor-positive $(\mathrm{ER}+)$ /progesterone receptor-negative $(\mathrm{PgR}-)$ /human epidermal growth factor receptor-2-positive (HER2+) Stage IIIA breast cancer ( $3 \mathrm{~cm}$ moderately differentiated infiltrating ductal carcinoma) detected by autopalpation. Physical examination revealed a 1-cm axillary lymph node (infiltration proven by histology). Her oncologist would prefer to begin neoadjuvant therapy as soon as possible but is concerned about cardiac adverse events associated with therapy that may affect this patient.
\end{abstract}

Fig. 3 Hypothetical case study 2

\section{The future of monitoring and treatment for HER2-therapy-associated cardiotoxicity}

With more patients living longer during and after cancer treatment, there is a need for earlier and more accurate detection of cardiotoxicity. Cardiac function in clinical trials and retrospective analyses is generally analyzed using LVEF changes, with symptomatic $\mathrm{CHF}$ as an endpoint. Although LVEF monitoring is the current standard of care to monitor for cardiotoxicity, its accuracy, reproducibility, relevance, and timeliness in predicting cardiac dysfunction remain topics of debate $[57,59]$. There are a number of ongoing clinical studies and registries assessing the cardiac monitoring techniques and biomarkers in patients with HER2+ breast cancer (Table 3 ).

Echocardiography and cardiac magnetic resonance (CMR) are the current standards for assessing LVEF due to ease of use, widespread availability, and lack of radiation [53]. Techniques to improve the reliability and reproducibility of echocardiography, such as 3-dimensional and contrast echocardiography, are under investigation [72, 73]. Three-dimensional echocardiography is preferable due to high reproducibility but may not be widely available and may also rely on high-quality images and a knowledgeable operator [53]. Contrast echocardiography provides more accurate estimations of ejection fraction and may be particularly useful in patients with a poor first reading by providing enhanced definition and improving interobserver reliability [53, 72]. Measurements of myocardial strain are an active area of research and have been demonstrated to be a reliable early detector of chemotherapy-induced cardiotoxicity [74]. Tissue Doppler imaging (TDI), used to measure systolic and diastolic velocity, may provide more sensitive measures of early changes predictive of cancer therapy-related heart 


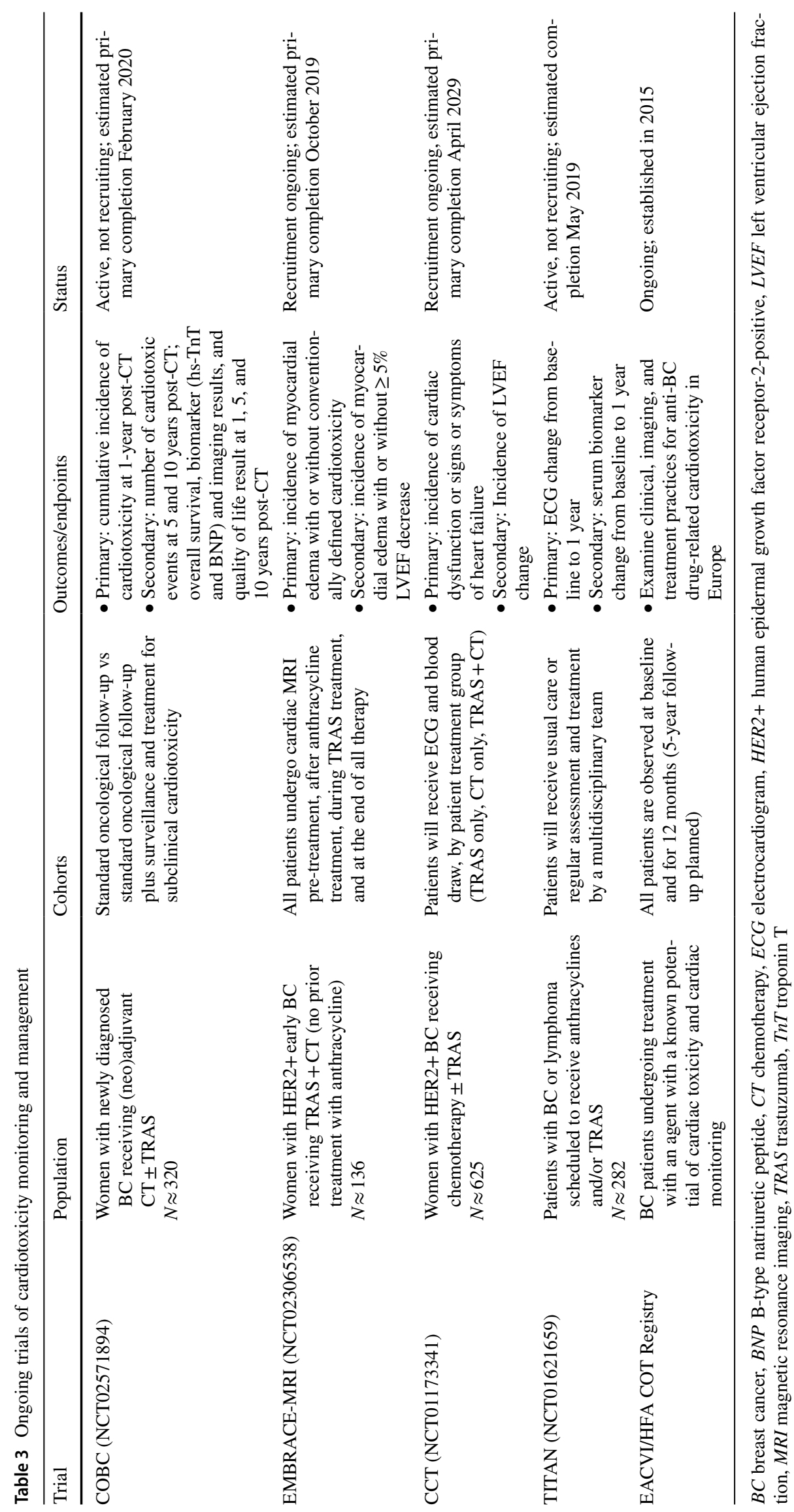


failure, even in the absence of LVEF changes [75]. Although TDI should be considered, its use is limited by both availability and technical issues such as reproducibility $[53,75]$. Techniques for the measurements of global longitudinal strain (GLS), such as speckle tracking echocardiography (STE), may also provide an easily quantifiable mechanism for early detection of cardiotoxicity before LVEF decrease is noted [74]. Further research is needed to determine whether the benefit of these enhanced cardiographic techniques warrants the additional cost over traditional 2-dimensional echocardiography. Regardless of the modality chosen, the universal recommendation is to use the same technique for baseline assessment and all subsequent follow-up assessments to obtain the most accurate comparisons.

Circulating biomarkers of cardiac damage may provide even earlier and more sensitive detection of potential cardiac dysfunction than imaging techniques. Troponin-1, a marker of cardiomyocyte injury that precedes decreased LVEF, is detected at elevated levels in patients receiving HER2-targeted therapy with chemotherapy for breast cancer $[76,77]$. Using a combination of both troponin-1 levels and advanced imaging such as STE may provide early indications of LVEF decrease during trastuzumab treatment and may be beneficial for patients at high risk of cardiotoxicity $[18,52,53]$. Other biomarkers, including myeloperoxidase (MPO), C-reactive protein (CRP), and growth differentiation factor-15 (GDF-15) are under investigation for patients with cancer receiving potentially cardiotoxic therapy [76, 78]. The encouraging results of initial studies into biomarkers of cardiac injury warrant their further assessment in prospective clinical studies to determine optimal selection of measurement, timing of analysis, and appropriate intervention based on results $[18,53]$.

\section{Conclusions}

The past several decades have seen a rapid increase in the number of agents available to treat HER2+ breast cancer. This has led to dramatic increases in disease-free survival for patients who undergo adjuvant therapy for early-stage disease and in longer lives for patients with metastatic disease (who thereby are often receiving treatment for prolonged periods). Although enormously beneficial in terms of disease control, these therapies are associated with some risks. The initial phase 3 trial of trastuzumab revealed an unexpected significant increase in cardiotoxicity. Additional HER2-targeted therapies, including lapatinib, T-DM1, pertuzumab, and others, also noted increases in cardiotoxic outcomes, albeit at less frequent rates. As these therapies are often administered in combination, or sequentially with other potentially cardiotoxic chemotherapy agents such as anthracyclines, special attention is necessary to manage and mitigate these potentially serious outcomes.

With years of experience in the clinical trials setting and in real-world practice, clinical practice guidelines have been developed for the optimal management of cardiotoxicity with HER2-targeted therapies. Routine cardiac monitoring, dose modification or cessation of anticancer therapies, and pharmacologic treatment of early cardiotoxicity all contribute to improved cardiac outcomes in patients with HER2+breast cancer. However, for patients with pre-existing cardiac conditions or those who develop cardiotoxicity during the course of therapy, there remains an urgent need for effective treatments. A number of ongoing studies will provide additional information on improved monitoring techniques, interventions, and strategies for the optimal treatment of patients with cardiac disease at baseline. We eagerly await the results of such trials, which will help improve the treatment of HER $2+$ breast cancer in an expanded number of patients.

Acknowledgements Medical editorial assistance was provided by Shalini Murthy, PhD, of Healthcare Consultancy Group LLC, and funded by Novartis Pharmaceuticals Corporation.

Funding Novartis Pharmaceuticals (for medical editorial assistance)

Data availability Data sharing not applicable to this article as no datasets were generated or analyzed during the current study.

\section{Compliance with ethical standards}

Conflict of interest Guy Jerusalem has received honoraria from Novartis, Roche, Lilly, Pfizer, Amgen, Bristol-Myers Squibb; research funding from Novartis and Roche; travel accommodations from Novartis, Roche, Pfizer, Lilly, Amgen, Bristol-Myers Squibb, AstraZeneca; served in a consulting or advisory role for Novartis, Celgene, Roche, Amgen, Pfizer, Bristol-Myers Squibb, Lilly, Puma Biotechnology, Astra-Zeneca, Daiichi Sankyo, and Abbvie. Patrizio Lancellotti has nothing to disclose. Sung-Bae Kim has received institutional research funding from Novartis, Sanofi-Aventis, Kyowa-Kirin Inc, and Dongkook Pharma Co. Ltd.

Ethical approval This article does not contain any studies with human participants performed by any of the authors.

Open Access This article is distributed under the terms of the Creative Commons Attribution 4.0 International License (http://creativeco mmons.org/licenses/by/4.0/), which permits unrestricted use, distribution, and reproduction in any medium, provided you give appropriate credit to the original author(s) and the source, provide a link to the Creative Commons license, and indicate if changes were made.

\section{References}

1. Howlader N, Altekruse SF, Li CI, Chen VW, Clarke CA, Ries LA, Cronin KA (2014) US incidence of breast cancer subtypes defined 
by joint hormone receptor and HER2 status. J Natl Cancer Inst 106(5). https://doi.org/10.1093/jnci/dju055

2. Loibl S, Gianni L (2017) HER2-positive breast cancer. Lancet 389(10087):2415-2429. https://doi.org/10.1016/S0140 $-6736(16) 32417-5$

3. Slamon DJ, Leyland-Jones B, Shak S, Fuchs H, Paton V, Bajamonde A, Fleming T, Eiermann W, Wolter J, Pegram M, Baselga J, Norton L (2001) Use of chemotherapy plus a monoclonal antibody against HER 2 for metastatic breast cancer that overexpresses HER2. N Engl J Med 344(11):783-792. https://doi.org/10.1056/ NEJM200103153441101

4. Geyer CE, Forster J, Lindquist D, Chan S, Romieu CG, Pienkowski T, Jagiello-Gruszfeld A, Crown J, Chan A, Kaufman B, Skarlos D, Campone M, Davidson N, Berger M, Oliva C, Rubin SD, Stein S, Cameron D (2006) Lapatinib plus capecitabine for HER2-positive advanced breast cancer. N Engl J Med 355(26):2733-2743. https://doi.org/10.1056/NEJMoa064320

5. Johnston S, Pippen J Jr, Pivot X, Lichinitser M, Sadeghi S, Dieras V, Gomez HL, Romieu G, Manikhas A, Kennedy MJ, Press MF, Maltzman J, Florance A, O'Rourke L, Oliva C, Stein S, Pegram M (2009) Lapatinib combined with letrozole versus letrozole and placebo as first-line therapy for postmenopausal hormone receptor-positive metastatic breast cancer. J Clin Oncol 27(33):55385546. https://doi.org/10.1200/JCO.2009.23.3734

6. Blackwell KL, Burstein HJ, Storniolo AM, Rugo H, Sledge G, Koehler M, Ellis C, Casey M, Vukelja S, Bischoff J, Baselga J, O'Shaughnessy J (2010) Randomized study of lapatinib alone or in combination with trastuzumab in women with ErbB2-positive, trastuzumab-refractory metastatic breast cancer. J Clin Oncol 28(7):1124-1130. https://doi.org/10.1200/JCO.2008.21.4437

7. Baselga J, Bradbury I, Eidtmann H, Di Cosimo S, de Azambuja E, Aura C, Gomez H, Dinh P, Fauria K, Van Dooren V, Aktan G, Goldhirsch A, Chang TW, Horvath Z, Coccia-Portugal M, Domont J, Tseng LM, Kunz G, Sohn JH, Semiglazov V, Lerzo G, Palacova M, Probachai V, Pusztai L, Untch M, Gelber RD, Piccart-Gebhart M, NeoALTTO Study Team (2012) Lapatinib with trastuzumab for HER2-positive early breast cancer (NeoALTTO): a randomised, open-label, multicentre, phase 3 trial. Lancet 379(9816):633-640. https://doi.org/10.1016/S0140 -6736(11)61847-3

8. Piccart-Gebhart M, Holmes E, Baselga J, de Azambuja E, Dueck AC, Viale G, Zujewski JA, Goldhirsch A, Armour A, Pritchard KI, McCullough AE, Dolci S, McFadden E, Holmes AP, Tonghua L, Eidtmann H, Dinh P, Di Cosimo S, Harbeck N, Tjulandin S, Im YH, Huang CS, Dieras V, Hillman DW, Wolff AC, Jackisch C, Lang I, Untch M, Smith I, Boyle F, Xu B, Gomez H, Suter T, Gelber RD, Perez EA (2016) Adjuvant lapatinib and trastuzumab for early human epidermal growth factor receptor 2-positive breast cancer: results from the randomized phase III adjuvant lapatinib and/or trastuzumab treatment optimization trial. J Clin Oncol 34(10):1034-1042. https://doi.org/10.1200/JCO.2015.62.1797

9. Swain SM, Baselga J, Kim SB, Ro J, Semiglazov V, Campone M, Ciruelos E, Ferrero JM, Schneeweiss A, Heeson S, Clark E, Ross G, Benyunes MC, Cortes J, CLEOPATRA Study Group (2015) Pertuzumab, trastuzumab, and docetaxel in HER2-positive metastatic breast cancer. N Engl J Med 372(8):724-734. https://doi. org/10.1056/nejmoa1413513

10. von Minckwitz G, Procter M, de Azambuja E, Zardavas D, Benyunes M, Viale G, Suter T, Arahmani A, Rouchet N, Clark E, Knott A, Lang I, Levy C, Yardley DA, Bines J, Gelber RD, Piccart M, Baselga J, APHINITY Steering Committee and Investigators (2017) Adjuvant pertuzumab and trastuzumab in early HER2positive breast cancer. N Engl J Med 377(2):122-131. https://doi. org/10.1056/NEJMoa1703643

11. Gianni L, Pienkowski T, Im YH, Tseng LM, Liu MC, Lluch A, Staroslawska E, de la Haba-Rodriguez J, Im SA, Pedrini JL,
Poirier B, Morandi P, Semiglazov V, Srimuninnimit V, Bianchi GV, Magazzu D, McNally V, Douthwaite H, Ross G, Valagussa $\mathrm{P}$ (2016) 5-year analysis of neoadjuvant pertuzumab and trastuzumab in patients with locally advanced, inflammatory, or earlystage HER2-positive breast cancer (NeoSphere): a multicentre, open-label, phase 2 randomised trial. Lancet Oncol 17(6):791800. https://doi.org/10.1016/S1470-2045(16)00163-7

12. Verma S, Miles D, Gianni L, Krop IE, Welslau M, Baselga J, Pegram M, Oh DY, Dieras V, Guardino E, Fang L, Lu MW, Olsen S, Blackwell K, EMILIA Study Group (2012) Trastuzumab emtansine for HER2-positive advanced breast cancer. N Engl J Med 367(19):1783-1791. https://doi.org/10.1056/nejmo a1209124

13. Krop IE, Kim SB, Martin AG, LoRusso PM, Ferrero JM, Badovinac-Crnjevic T, Hoersch S, Smitt M, Wildiers H (2017) Trastuzumab emtansine versus treatment of physician's choice in patients with previously treated HER2-positive metastatic breast cancer (TH3RESA): final overall survival results from a randomised open-label phase 3 trial. Lancet Oncol 18(6):743754. https://doi.org/10.1016/S1470-2045(17)30313-3

14. Awada A, Colomer R, Inoue K, Bondarenko I, Badwe RA, Demetriou G, Lee SC, Mehta AO, Kim SB, Bachelot T, Goswami C, Deo S, Bose R, Wong A, Xu F, Yao B, Bryce R, Carey LA (2016) Neratinib plus paclitaxel vs trastuzumab plus paclitaxel in previously untreated metastatic ERBB2-positive breast cancer: the NEfERT-T randomized clinical trial. JAMA Oncol 2(12):1557-1564. https://doi.org/10.1001/jamaoncol.2016.0237

15. Martin M, Holmes FA, Ejlertsen B, Delaloge S, Moy B, Iwata $\mathrm{H}$, von Minckwitz G, Chia SKL, Mansi J, Barrios CH, Gnant M, Tomasevic Z, Denduluri N, Separovic R, Gokmen E, Bashford A, Ruiz Borrego M, Kim SB, Jakobsen EH, Ciceniene A, Inoue K, Overkamp F, Heijns JB, Armstrong AC, Link JS, Joy AA, Bryce R, Wong A, Moran S, Yao B, Xu F, Auerbach A, Buyse M, Chan A, ExteNET Study Group (2017) Neratinib after trastuzumab-based adjuvant therapy in HER2-positive breast cancer (ExteNET): 5-year analysis of a randomised, double-blind, placebo-controlled, phase 3 trial. Lancet Oncol 18(12):1688-1700. https://doi.org/10.1016/S1470-2045(17)30717-9

16. Giordano SH, Temin S, Kirshner JJ, Chandarlapaty S, Crews JR, Davidson NE, Esteva FJ, Gonzalez-Angulo AM, Krop I, Levinson J, Lin NU, Modi S, Patt DA, Perez EA, Perlmutter J, Ramakrishna N, Winer EP, American Society of Clinical Oncology (2014) Systemic therapy for patients with advanced human epidermal growth factor receptor 2-positive breast cancer: American Society of Clinical Oncology clinical practice guideline. J Clin Oncol 32(19):2078-2099. https://doi.org/10.1200/ jco.2013.54.0948

17. Cardoso F, Costa A, Senkus E, Aapro M, Andre F, Barrios CH, Bergh J, Bhattacharyya G, Biganzoli L, Cardoso MJ, Carey L, Corneliussen-James D, Curigliano G, Dieras V, El Saghir N, Eniu A, Fallowfield L, Fenech D, Francis P, Gelmon K, Gennari A, Harbeck N, Hudis C, Kaufman B, Krop I, Mayer M, Meijer H, Mertz S, Ohno S, Pagani O, Papadopoulos E, Peccatori F, PenaultLlorca F, Piccart MJ, Pierga JY, Rugo H, Shockney L, Sledge G, Swain S, Thomssen C, Tutt A, Vorobiof D, Xu B, Norton L, Winer E (2017) 3rd ESO-ESMO international consensus guidelines for Advanced Breast Cancer (ABC 3). Ann Oncol 28(1):16-33. https ://doi.org/10.1093/annonc/mdw544

18. Curigliano G, Burstein HJ, E PW, Gnant M, Dubsky P, Loibl S, Colleoni M, Regan MM, Piccart-Gebhart M, Senn HJ, Thurlimann B, St. Gallen International Expert Consensus on the Primary Therapy of Early Breast Cancer, Andre F, Baselga J, Bergh J, Bonnefoi H, Brucker SY, Cardoso F, Carey L, Ciruelos E, Cuzick J, Denkert C, Di Leo A, Ejlertsen B, Francis P, Galimberti V, Garber J, Gulluoglu B, Goodwin P, Harbeck N, Hayes DF, Huang CS, Huober J, Hussein K, Jassem J, Jiang Z, Karlsson P, Morrow 
M, Orecchia R, Osborne KC, Pagani O, Partridge AH, Pritchard K, Ro J, Rutgers EJT, Sedlmayer F, Semiglazov V, Shao Z, Smith I, Toi M, Tutt A, Viale G, Watanabe T, Whelan TJ, Xu B (2017) De-escalating and escalating treatments for early-stage breast cancer: the St. Gallen International Expert Consensus Conference on the Primary Therapy of Early Breast Cancer 2017. Ann Oncol 28(8):1700-1712. https://doi.org/10.1093/annonc/mdx308

19. National Comprehensive Cancer Network Breast Cancer (Version 3.2017). https://www.nccn.org/professionals/physician_gls/pdf/ breast.pdf. Accessed 22 Feb 2019

20. Yood MU, Wells KE, Alford SH, Dakki H, Beiderbeck AB, Hurria A, Gross CP, Oliveria SA (2012) Cardiovascular outcomes in women with advanced breast cancer exposed to chemotherapy. Pharmacoepidemiol Drug Saf 21(8):818-827. https://doi. org/10.1002/pds.3239

21. Long HD, Lin YE, Zhang JJ, Zhong WZ, Zheng RN (2016) Risk of congestive heart failure in early breast cancer patients undergoing adjuvant treatment with trastuzumab: a meta-analysis. Oncologist 21(5):547-554. https://doi.org/10.1634/theoncolog ist.2015-0424

22. Suter TM, Ewer MS (2013) Cancer drugs and the heart: importance and management. Eur Heart J 34(15):1102-1111. https:// doi.org/10.1093/eurheartj/ehs181

23. Seidman A, Hudis C, Pierri MK, Shak S, Paton V, Ashby M, Murphy M, Stewart SJ, Keefe D (2002) Cardiac dysfunction in the trastuzumab clinical trials experience. J Clin Oncol 20(5):12151221. https://doi.org/10.1200/JCO.2002.20.5.1215

24. Balduzzi S, Mantarro S, Guarneri V, Tagliabue L, Pistotti V, Moja L, D'Amico R (2014) Trastuzumab-containing regimens for metastatic breast cancer. Cochrane Database Syst Rev (6):CD006242. https://doi.org/10.1002/14651858.cd006242.pub2

25. Perez EA, Koehler M, Byrne J, Preston AJ, Rappold E, Ewer MS (2008) Cardiac safety of lapatinib: pooled analysis of 3689 patients enrolled in clinical trials. Mayo Clin Proc 83(6):679-686. https://doi.org/10.4065/83.6.679

26. Blackwell KL, Burstein HJ, Storniolo AM, Rugo HS, Sledge G, Aktan G, Ellis C, Florance A, Vukelja S, Bischoff J, Baselga J, O'Shaughnessy J (2012) Overall survival benefit with lapatinib in combination with trastuzumab for patients with human epidermal growth factor receptor 2-positive metastatic breast cancer: final results from the EGF104900 Study. J Clin Oncol 30(21):25852592. https://doi.org/10.1200/JCO.2011.35.6725

27. Krop IE, Kim SB, Gonzalez-Martin A, LoRusso PM, Ferrero JM, Smitt M, Yu R, Leung AC, Wildiers H, TH3RESA study collaborators (2014) Trastuzumab emtansine versus treatment of physician's choice for pretreated HER2-positive advanced breast cancer (TH3RESA): a randomised, open-label, phase 3 trial. Lancet Oncol 15(7):689-699. https://doi.org/10.1016/S1470 -2045(14)70178-0

28. Krop IE, Suter TM, Dang CT, Dirix L, Romieu G, Zamagni C, Citron ML, Campone M, Xu N, Smitt M, Gianni L (2015) Feasibility and cardiac safety of trastuzumab emtansine after anthracycline-based chemotherapy as (neo)adjuvant therapy for human epidermal growth factor receptor 2-positive early-stage breast cancer. J Clin Oncol 33(10):1136-1142. https://doi.org/10.1200/ JCO.2014.58.7782

29. Perez EA, Barrios C, Eiermann W, Toi M, Im YH, Conte P, Martin M, Pienkowski T, Pivot X, Burris H 3rd, Petersen JA, Stanzel S, Strasak A, Patre M, Ellis P (2017) Trastuzumab emtansine with or without pertuzumab versus trastuzumab plus taxane for human epidermal growth factor receptor 2-positive, advanced breast cancer: primary results from the Phase III MARIANNE study. J Clin Oncol 35(2):141-148. https://doi.org/10.1200/JCO.2016.67.4887

30. Zeglinski M, Ludke A, Jassal DS, Singal PK (2011) Trastuzumabinduced cardiac dysfunction: a 'dual-hit'. Exp Clin Cardiol 16(3):70-74
31. Gordon LI, Burke MA, Singh AT, Prachand S, Lieberman ED, Sun L, Naik TJ, Prasad SV, Ardehali H (2009) Blockade of the erbB2 receptor induces cardiomyocyte death through mitochondrial and reactive oxygen species-dependent pathways. J Biol Chem 284(4):2080-2087. https://doi.org/10.1074/jbc.M8045 70200

32. Yu AF, Mukku RB, Verma S, Liu JE, Oeffinger KC, Steingart RM, Hudis CA, Dang CT (2017) Cardiac safety of non-anthracycline trastuzumab-based therapy for HER2-positive breast cancer. Breast Cancer Res Treat 166(1):241-247. https://doi.org/10.1007/ s10549-017-4362-x

33. Marinko T, Dolenc J, Bilban-Jakopin C (2014) Cardiotoxicity of concomitant radiotherapy and trastuzumab for early breast cancer. Radiol Oncol 48(2):105-112. https://doi.org/10.2478/ raon-2013-0040

34. Naumann D, Rusius V, Margiotta C, Nevill A, Carmichael A, Rea D, Sintler M (2013) Factors predicting trastuzumab-related cardiotoxicity in a real-world population of women with HER2+ breast cancer. Anticancer Res 33(4):1717-1720

35. Rayson D, Richel D, Chia S, Jackisch C, van der Vegt S, Suter T (2008) Anthracycline-trastuzumab regimens for HER2/neu-overexpressing breast cancer: current experience and future strategies. Ann Oncol 19(9):1530-1539. https://doi.org/10.1093/annon $\mathrm{c} / \mathrm{mdn} 292$

36. Seferina SC, de Boer M, Derksen MW, van den Berkmortel F, van Kampen RJ, van de Wouw AJ, Joore M, Peer PG, Voogd AC, Tjan-Heijnen VC (2016) Cardiotoxicity and cardiac monitoring during adjuvant trastuzumab in daily Dutch practice: a study of the Southeast Netherlands Breast Cancer Consortium. Oncologist 21(5):555-562. https://doi.org/10.1634/theoncologist.2015-0230

37. Tarantini L, Cioffi G, Gori S, Tuccia F, Boccardi L, Bovelli D, Lestuzzi C, Maurea N, Oliva S, Russo G, Faggiano P, Italian Cardio-Oncologic Network (2012) Trastuzumab adjuvant chemotherapy and cardiotoxicity in real-world women with breast cancer. J Card Fail 18(2):113-119. https://doi.org/10.1016/j.cardf ail.2011.10.015

38. Herceptin (trastuzumab) [package insert] (2017). Genentech, Inc., South San Francisco, CA

39. Herceptin (trastuzumab) [summary of product characteristics] (2017). Roche Registration Limited, Welwyn Garden City, UK

40. Tykerb (lapatinib) [package insert] (2017). Novartis Pharmaceuticals, East Hanover, NJ

41. Tyverb (lapatinib) [summary of product characteristics] (2017). Novartis Europharm Limited, Camberley, UK

42. Yu AF, Singh JC, Wang R, Liu JE, Eaton A, Oeffinger KC, Steingart RM, Hudis CA, Dang CT (2017) Cardiac safety of dual anti-HER2 therapy in the neoadjuvant setting for treatment of HER2-positive breast cancer. Oncologist 22(6):642-647. https:// doi.org/10.1634/theoncologist.2016-0406

43. Perjeta (pertuzumab) [package insert] (2017). Genentech, Inc., South San Francisco, CA

44. Perjeta (pertuzumab) [summary of product characteristics] (2017). Roche Registration Limited, Welwyn Garden City, UK

45. Kadcyla (ado-trastuzumab emtansine) [package insert] (2017). Genentech, Inc, South San Francisco, CA

46. Kast K, Link T, Friedrich K, Petzold A, Niedostatek A, Schoffer O, Werner C, Klug SJ, Werner A, Gatzweiler A, Richter B, Baretton G, Wimberger P (2015) Impact of breast cancer subtypes and patterns of metastasis on outcome. Breast Cancer Res Treat 150(3):621-629. https://doi.org/10.1007/s10549-015-3341-3

47. Vici P, Pizzuti L, Michelotti A, Sperduti I, Natoli C, Mentuccia L, Di Lauro L, Sergi D, Marchetti P, Santini D, Magnolfi E, Iezzi L, Moscetti L, Fabbri A, Cassano A, Grassadonia A, Omarini C, Piacentini F, Botticelli A, Bertolini I, Scinto AF, Zampa G, Mauri M, D’Onofrio L, Sini V, Barba M, Maugeri-Sacca M, Rossi E, Landucci E, Tomao S, Alberti AM, Giotta F, Ficorella C, Adamo 
V, Russo A, Lorusso V, Cannita K, Barni S, Laudadio L, Greco F, Garrone O, Della Giulia M, Marolla P, Sanguineti G, Di Cocco B, Ciliberto G, De Maria R, Gamucci T (2017) A retrospective multicentric observational study of trastuzumab emtansine in HER2 positive metastatic breast cancer: a real-world experience. Oncotarget 8(34):56921-56931. https://doi.org/10.18632/oncot arget.18176

48. Kadcyla (trastuzumab emtansine) [summary of product characteristics] (2017). Roche Registration Limited, Welwyn Garden City, UK

49. Burstein HJ, Sun Y, Dirix LY, Jiang Z, Paridaens R, Tan AR, Awada A, Ranade A, Jiao S, Schwartz G, Abbas R, Powell C, Turnbull K, Vermette J, Zacharchuk C, Badwe R (2010) Neratinib, an irreversible ErbB receptor tyrosine kinase inhibitor, in patients with advanced ErbB2-positive breast cancer. J Clin Oncol 28(8):1301-1307. https://doi.org/10.1200/ JCO.2009.25.8707

50. Chan A, Delaloge S, Holmes FA, Moy B, Iwata H, Harvey VJ, Robert NJ, Silovski T, Gokmen E, von Minckwitz G, Ejlertsen B, Chia SK, Mansi J, Barrios CH, Gnant M, Buyse M, Gore I, Smith J 2nd, Harker G, Masuda N, Petrakova K, Zotano AG, Iannotti N, Rodriguez G, Tassone P, Wong A, Bryce R, Ye Y, Yao B, Martin M, ExteNET Study Group (2016) Neratinib after trastuzumabbased adjuvant therapy in patients with HER2-positive breast cancer (ExteNET): a multicentre, randomised, double-blind, placebocontrolled, phase 3 trial. Lancet Oncol 17(3):367-377. https://doi. org/10.1016/S1470-2045(15)00551-3

51. Nerlynx (neratinib) [package insert] (2017). Puma Biotechnology, Los Angeles, CA

52. Armenian SH, Lacchetti C, Barac A, Carver J, Constine LS, Denduluri N, Dent S, Douglas PS, Durand JB, Ewer M, Fabian C, Hudson M, Jessup M, Jones LW, Ky B, Mayer EL, Moslehi J, Oeffinger K, Ray K, Ruddy K, Lenihan D (2017) Prevention and monitoring of cardiac dysfunction in survivors of adult cancers: American Society of Clinical Oncology clinical practice guideline. J Clin Oncol 35(8):893-911. https://doi.org/10.1200/ JCO.2016.70.5400

53. Zamorano JL, Lancellotti P, Rodriguez Munoz D, Aboyans V, Asteggiano R, Galderisi M, Habib G, Lenihan DJ, Lip GY, Lyon AR, Lopez Fernandez T, Mohty D, Piepoli MF, Tamargo J, Torbicki A, Suter TM, ESC Scientific Document Group (2016) 2016 ESC Position Paper on cancer treatments and cardiovascular toxicity developed under the auspices of the ESC Committee for Practice Guidelines: the Task Force for cancer treatments and cardiovascular toxicity of the European Society of Cardiology (ESC). Eur Heart J 37(36):2768-2801. https://doi.org/10.1093/ eurheartj/ehw211

54. Lynce F, Barac A, Tan MT, Asch FM, Smith KL, Dang C, Isaacs C, Swain SM (2017) SAFE-HEaRt: rationale and design of a pilot study investigating cardiac safety of HER2 targeted therapy in patients with HER2-positive breast cancer and reduced left ventricular function. Oncologist 22(5):518-525. https://doi. org/10.1634/theoncologist.2016-0412

55. Chavez-MacGregor M, Niu J, Zhang N, Elting LS, Smith BD, Banchs J, Hortobagyi GN, Giordano SH (2015) Cardiac monitoring during adjuvant trastuzumab-based chemotherapy among older patients with breast cancer. J Clin Oncol 33(19):2176-2183. https://doi.org/10.1200/JCO.2014.58.9465

56. Visser A, van de Ven EM, Ruczynski LI, Blaisse RJ, van Halteren HK, Aben K, van Laarhoven HW (2016) Cardiac monitoring during adjuvant trastuzumab therapy: guideline adherence in clinical practice. Acta Oncol 55(4):423-429. https://doi. org/10.3109/0284186X.2015.1068444

57. Dang CT, Yu AF, Jones LW, Liu J, Steingart RM, Argolo DF, Norton L, Hudis CA (2016) Cardiac surveillance guidelines for trastuzumab-containing therapy in early-stage breast cancer: getting to the heart of the matter. J Clin Oncol 34(10):1030-1033. https://doi.org/10.1200/JCO.2015.64.5515

58. Plana JC, Galderisi M, Barac A, Ewer MS, Ky B, Scherrer-Crosbie M, Ganame J, Sebag IA, Agler DA, Badano LP, Banchs J, Cardinale D, Carver J, Cerqueira M, DeCara JM, Edvardsen T, Flamm SD, Force T, Griffin BP, Jerusalem G, Liu JE, Magalhaes A, Marwick T, Sanchez LY, Sicari R, Villarraga HR, Lancellotti $\mathrm{P}$ (2014) Expert consensus for multimodality imaging evaluation of adult patients during and after cancer therapy: a report from the American Society of Echocardiography and the European Association of Cardiovascular Imaging. J Am Soc Echocardiogr 27(9):911-939. https://doi.org/10.1016/j.echo.2014.07.012

59. Davis CC, Zelnak A, Eley JW, Goldstein DA, Switchenko JM, McKibbin T (2016) Clinical utility of routine cardiac monitoring in breast cancer patients receiving trastuzumab. Ann Pharmacother 50(9):712-717. https://doi.org/10.1177/1060028016654160

60. Truong SR, Barry WT, Moslehi JJ, Baker EL, Mayer EL, Partridge AH (2016) Evaluating the utility of baseline cardiac function screening in early-stage breast cancer treatment. Oncologist 21(6):666-670. https://doi.org/10.1634/theoncologist.2015-0449

61. Henriksen PA (2017) Anthracycline cardiotoxicity: an update on mechanisms, monitoring and prevention. Heart 2:89. https://doi. org/10.1136/heartjnl-2017-312103

62. Kalam K, Marwick TH (2013) Role of cardioprotective therapy for prevention of cardiotoxicity with chemotherapy: a systematic review and meta-analysis. Eur J Cancer 49(13):2900-2909. https ://doi.org/10.1016/j.ejca.2013.04.030

63. Pituskin E, Mackey JR, Koshman S, Jassal D, Pitz M, Haykowsky MJ, Pagano JJ, Chow K, Thompson RB, Vos LJ, Ghosh S, Oudit GY, Ezekowitz JA, Paterson DI (2017) Multidisciplinary Approach to Novel Therapies in Cardio-Oncology Research (MANTICORE 101-Breast): a randomized trial for the prevention of trastuzumab-associated cardiotoxicity. J Clin Oncol 35(8):870877. https://doi.org/10.1200/JCO.2016.68.7830

64. Meattini I, Curigliano G, Terziani F, Becherini C, Airoldi M, Allegrini G, Amoroso D, Barni S, Bengala C, Guarneri V, Marchetti P, Martella F, Piovano P, Vannini A, Desideri I, Tarquini R, Galanti G, Barletta G, Livi L (2017) SAFE trial: an ongoing randomized clinical study to assess the role of cardiotoxicity prevention in breast cancer patients treated with anthracyclines with or without trastuzumab. Med Oncol 34(5):75. https://doi. org/10.1007/s12032-017-0938-x

65. Herrera AP, Snipes SA, King DW, Torres-Vigil I, Goldberg DS, Weinberg AD (2010) Disparate inclusion of older adults in clinical trials: priorities and opportunities for policy and practice change. Am J Public Health 100(suppl 1):S105-S112. https://doi. org/10.2105/AJPH.2009.162982

66. Serrano C, Cortes J, De Mattos-Arruda L, Bellet M, Gomez P, Saura C, Perez J, Vidal M, Munoz-Couselo E, Carreras MJ, Sanchez-Olle G, Tabernero J, Baselga J, Di Cosimo S (2012) Trastuzumab-related cardiotoxicity in the elderly: a role for cardiovascular risk factors. Ann Oncol 23(4):897-902. https://doi. org/10.1093/annonc/mdr348

67. Leung HW, Chan AL (2015) Trastuzumab-induced cardiotoxicity in elderly women with HER-2-positive breast cancer: a meta-analysis of real-world data. Expert Opin Drug Saf 14(11):1661-1671. https://doi.org/10.1517/14740338.2015.1089231

68. Chavez-MacGregor M, Zhang N, Buchholz TA, Zhang Y, Niu J, Elting L, Smith BD, Hortobagyi GN, Giordano SH (2013) Trastuzumab-related cardiotoxicity among older patients with breast cancer. J Clin Oncol 31(33):4222-4228. https://doi.org/10.1200/ JCO.2013.48.7884

69. Benjamin EJ, Blaha MJ, Chiuve SE, Cushman M, Das SR, Deo R, de Ferranti SD, Floyd J, Fornage M, Gillespie C, Isasi CR, Jimenez MC, Jordan LC, Judd SE, Lackland D, Lichtman JH, Lisabeth L, Liu S, Longenecker CT, Mackey RH, Matsushita 
K, Mozaffarian D, Mussolino ME, Nasir K, Neumar RW, Palaniappan L, Pandey DK, Thiagarajan RR, Reeves MJ, Ritchey M, Rodriguez CJ, Roth GA, Rosamond WD, Sasson C, Towfighi A, Tsao CW, Turner MB, Virani SS, Voeks JH, Willey JZ, Wilkins JT, Wu JH, Alger HM, Wong SS, Muntner P, American Heart Association Statistics Committee, Stroke Statistics Subcommittee (2017) Heart disease and stroke statistics-2017 update: a report from the American Heart Association. Circulation 135(10):e146e603. https://doi.org/10.1161/cir.0000000000000485

70. Sarfati D, Koczwara B, Jackson C (2016) The impact of comorbidity on cancer and its treatment. CA Cancer J Clin 66(4):337-350. https://doi.org/10.3322/caac.21342

71. Herrmann J, Lerman A, Sandhu NP, Villarraga HR, Mulvagh SL, Kohli M (2014) Evaluation and management of patients with heart disease and cancer: cardio-oncology. Mayo Clin Proc 89(9):12871306. https://doi.org/10.1016/j.mayocp.2014.05.013

72. Hoffmann R, von Bardeleben S, ten Cate F, Borges AC, Kasprzak J, Firschke C, Lafitte S, Al-Saadi N, Kuntz-Hehner S, Engelhardt M, Becher H, Vanoverschelde JL (2005) Assessment of systolic left ventricular function: a multi-centre comparison of cineventriculography, cardiac magnetic resonance imaging, unenhanced and contrast-enhanced echocardiography. Eur Heart J 26(6):607616. https://doi.org/10.1093/eurheartj/ehi083

73. Takuma S, Ota T, Muro T, Hozumi T, Sciacca R, Di Tullio MR, Blood DK, Yoshikawa J, Homma S (2001) Assessment of left ventricular function by real-time 3-dimensional echocardiography compared with conventional noninvasive methods. J Am Soc Echocardiogr 14(4):275-284

74. Thavendiranathan P, Poulin F, Lim KD, Plana JC, Woo A, Marwick TH (2014) Use of myocardial strain imaging by echocardiography for the early detection of cardiotoxicity in patients during and after cancer chemotherapy: a systematic review. J Am Coll Cardiol 63((25 Pt A)):2751-2768. https://doi.org/10.1016/j. jacc.2014.01.073
75. Gulati G, Zhang KW, Scherrer-Crosbie M, Ky B (2014) Cancer and cardiovascular disease: the use of novel echocardiography measures to predict subsequent cardiotoxicity in breast cancer treated with anthracyclines and trastuzumab. Curr Heart Fail Rep 11(4):366-373. https://doi.org/10.1007/s11897-014-0214-8

76. Ky B, Putt M, Sawaya H, French B, Januzzi JL Jr, Sebag IA, Plana JC, Cohen V, Banchs J, Carver JR, Wiegers SE, Martin RP, Picard MH, Gerszten RE, Halpern EF, Passeri J, Kuter I, ScherrerCrosbie M (2014) Early increases in multiple biomarkers predict subsequent cardiotoxicity in patients with breast cancer treated with doxorubicin, taxanes, and trastuzumab. J Am Coll Cardiol 63(8):809-816. https://doi.org/10.1016/j.jacc.2013.10.061

77. Morris PG, Chen C, Steingart R, Fleisher M, Lin N, Moy B, Come S, Sugarman S, Abbruzzi A, Lehman R, Patil S, Dickler M, McArthur HL, Winer E, Norton L, Hudis CA, Dang CT (2011) Troponin I and C-reactive protein are commonly detected in patients with breast cancer treated with dose-dense chemotherapy incorporating trastuzumab and lapatinib. Clin Cancer Res 17(10):3490-3499. https://doi.org/10.1158/1078-0432. CCR-10-1359

78. Putt M, Hahn VS, Januzzi JL, Sawaya H, Sebag IA, Plana JC, Picard MH, Carver JR, Halpern EF, Kuter I, Passeri J, Cohen V, Banchs J, Martin RP, Gerszten RE, Scherrer-Crosbie M, Ky B (2015) Longitudinal changes in multiple biomarkers are associated with cardiotoxicity in breast cancer patients treated with doxorubicin, taxanes, and trastuzumab. Clin Chem 61(9):1164-1172. https://doi.org/10.1373/clinchem.2015.241232

Publisher's Note Springer Nature remains neutral with regard to jurisdictional claims in published maps and institutional affiliations. 